\title{
ORIGINAL ARTICLE \\ Infections in the spinal cord-injured population: a systematic review
}

\author{
LY Garcia-Arguello ${ }^{1,2}$, JC O’Horo ${ }^{2,3}$, A Farrell ${ }^{4}$, R Blakney ${ }^{5,6}$, MR Sohail ${ }^{3}$, CT Evans ${ }^{5,6}$ and N Safdar ${ }^{7,8}$
}

Study Design: Spinal cord injury (SCI) patients are an increasing population due to recent military conflicts. SCl patients are at an increased risk of infection, but the epidemiology management and prevention strategies for these infections are unclear.

Objective: To review the incidence, microbiology and management of pneumonia, skin and soft tissue infections (SSTI), urinary tract infections (UTI) and bloodstream infections in the SCI population via literature review.

Methods: With the assistance of an experienced medical librarian, we developed a search strategy for the Ovid MEDLINE database and then adapted it for the Ovid Embase, Scopus and Web of Science databases. The databases were searched from their inception to April 2014 with no restrictions on language or time period. Data were extracted using a standardized form. All studies were reviewed by two independent investigators.

Results: Forty-one studies reporting on the described infections were identified. UTIs were the most commonly identified infections, but studies failed to identify consistently effective preventive strategies. SSTIs were also common, and the best preventive strategies focused on decubitus ulcer prevention and skin decolonization protocols. Pneumonia management and course were not significantly different from the general population. Bloodstream infections were associated with delays in recognition, and were most often secondary to UTI, pneumonia or SSTI.

Conclusion: There is a paucity of literature on consistently effective infection prevention strategies in SCl patients. Identification and implementation of evidence-based interventions that optimize prevention and management of infections in this patient population are needed.

Spinal Cord (2017) 55, 526-534; doi:10.1038/sc.2016.173; published online 6 December 2016

\section{INTRODUCTION}

Spinal cord injury (SCI) is a medically complex and life-disrupting condition affecting about a quarter million Americans. ${ }^{1}$ Its incidence varies widely from country to country, but $\sim 12000$ new cases are reported each year in the United States, with a recent increase most likely associated with present military conflicts. ${ }^{2,3} \mathrm{SCI}$ is the result of a trauma at any level of the spinal cord causing temporary or permanent damage. Motor vehicle accidents, falls and gunshot wounds are some of the most common causes of SCI among the civilian population, responsible for $39 \%, 28 \%$ and $14 \%$ of cases, respectively. ${ }^{3}$

Individuals with SCI are at high risk for both community-acquired and healthcare-associated infections due to factors such as frequent contact with the healthcare system and frequent and chronic use of invasive medical devices such as urinary and intravascular catheters. ${ }^{4,5}$ This population is also vulnerable by limitations in clearing the airway of secretions due to restricted breathing, and abnormal sensation leading to altered or absent symptoms to indicate early infection. Bloodstream infection (BSI) is one of the most common infections leading to hospital admission, followed by urinary tract infection (UTI), pneumonia, pressure ulcers and others. ${ }^{6}$ Respiratory tract infections are common during the initial hospitalizations with a reported frequency as high as $60 \%$. In contrast, UTIs and decubitus ulcers are more frequently encountered during (or causes of) subsequent hospitalizations with an incidence of $34 \%$ and $10 \%$, respectively. ${ }^{7-9}$ Pneumonia and BSI are the most common causes of mortality in this population, accounting for at least one-third of deaths during the first year after the injury and in the long term. ${ }^{10-13}$ Thus it is critical to identify risk factors, effective preventive strategies and treatment of infections in this highly vulnerable population.

Risk factors and causative organisms responsible for BSI in SCI patients depend on a number of factors. The acuity and severity of the SCI, the site of entry of the organism, the patient's home setting and concomitant device use all impact risk. Recent hospitalization also affects this, with $25 \%$ of re-hospitalizations caused by polymicrobial healthcare-associated infections. In re-admissions, enterococcal UTI was the most common, followed by anaerobic and Staphylococcal infections of pressure ulcers. ${ }^{8,9}$

Aside from mortality, these infections carry a high morbidity burden. UTIs have been implicated to cause acute kidney injury via inflammation and parenchymal destruction, and may in turn progress

${ }^{1}$ Department of Medicine, Division of Pulmonary and Critical Care Medicine, Mayo Clinic, Rochester, MN, USA; ${ }^{2}$ Multidisciplinary Epidemiology and Translational Research in Critical Care (METRIC) Group, Mayo Clinic, Rochester, MN, USA; ${ }^{3}$ Department of Medicine, Division of Infectious Diseases, Mayo Clinic, Rochester, MN, USA; ${ }^{4}$ Department of Library Services, Mayo Clinic, Rochester, MN, USA; ${ }^{5}$ Center of Innovation for Complex Chronic Healthcare and Spinal Cord Injury Quality Enhancement Research Initiative, Edward Hines Jr. VA Hospital, Hines, IL, USA; ${ }^{6}$ Department of Preventive Medicine and Center for Healthcare Studies, Institute for Public Health and Medicine, Feinberg School of Medicine, Northwestern University, Chicago, IL, USA; ${ }^{7}$ Department of Medicine, Section of Infectious Diseases, University of Wisconsin School of Medicine and Public Health, Madison, WI, USA and ${ }^{8}$ William S. Middleton Veterans Affairs Hospital, Madison, WI, USA

Correspondence: Dr JC O'Horo, Division of Infectious Diseases, Mayo Clinic, $2001^{\text {st }}$ st SW, Rochester, MN 55905, USA.

E-mail: Ohoro.john@mayo.edu

Received 4 April 2016; revised 27 October 2016; accepted 30 October 2016; published online 6 December 2016 
to chronic kidney disease. ${ }^{14}$ Pneumonia and BSI, particularly with resistant organisms, may require expensive courses of parenteral antibiotics.

As with the general population, rapid identification and treatment of severe infections with appropriate antimicrobials in the first $24 \mathrm{~h}$ of presentation is associated with better outcomes. ${ }^{9}$ However, the SCI population appears particularly vulnerable to misdiagnosis and inadequate empiric therapy, with one study finding nearly $40 \%$ of SCI patients did not receive adequate initial empiric antimicrobial therapy. ${ }^{15}$ Delayed diagnosis may increase risk of adverse outcomes. Understanding the epidemiology of infections in SCI patients, to effectively tailor treatment and prevention strategies is critical. ${ }^{16} \mathrm{We}$ sought to conduct a comprehensive systemic review of the literature regarding infections in the SCI population.

\section{METHODS}

With the assistance of an experienced medical librarian, we developed a search strategy for the Ovid MEDLINE database and then adapted it for the Ovid Embase, Cochrane Database of Systematic Reviews, Scopus and Web of Science databases. The searches were run in April 2014 with no restrictions on language or time period. MeSH terms and keywords were used including spinal cord injury, spinal contusions, lacerations, transections, trauma, quadriplegia and paraplegia, infection, multidrug-resistant organism, methicillin-resistant staphylococcus aureus (MRSA), staphylococcal, Clostridium difficile, E. coli, skin/pressure/decubitus sores or ulcers or wounds. The complete search strategy can be found in the Supplementary appendix. References of included studies were manually inspected for additional studies. The focus of our study was infections that were sequelae of SCI; as such, acute infections (for example, wound infections sustained during initial injury) were excluded.

Studies were identified as belonging to one of five general categories of infections: UTI, pneumonia, BSI, skin/soft tissue infections and a sub-category of healthcare-associated infections. Studies dealing exclusively with pressure ulcers without infectious complications were excluded, as were studies of urinary tract colonization/asymptomatic bacteriuria defined as the finding of bacteria without a clinical correlate of sepsis, fever, hypotension or leukocytosis. BSI was defined using the National Healthcare Safety Network definition for BSI and central line-associated bloodstream infection, where one or more cultures from a pathogenic organism or at least two cultures for a commensal organism must be positive to consider it a laboratory-confirmed BSI, and a central line must be in place 2 days before or within 2 days of removal to consider it a central line-associated bloodstream infection. ${ }^{17}$ Pneumonia definitions were considered acceptable if they included culture, laboratory or radiographic data correlated with signs/symptoms consistent with infection, for example, fever, hypoxemia or sepsis.

A standard form was used for data abstraction. Data abstracted from each study included the type(s) of infection studied, prevention practices, incidence, microbiology and treatment regimens. When available, outcome data, including mortality and length of stay, were abstracted as well.

\section{RESULTS}

The search strategy yielded 6026 distinct records. We excluded 5805 records on the basis of abstract and title information. This left 218 articles for full text review. Of these, 41 met inclusion criteria (Figure 1).

\section{Bloodstream infections (BSI)}

Seven studies were found addressing BSI, including four retrospective cohort studies $5,15,18,19$ and three case series. ${ }^{8,9,12}$ All were in adult populations, and four were in veteran's administration (VA) patient populations. ${ }^{12,15,18,19}$ Study characteristics, microbiology and findings are summarized in Table 1.

Three of the cohort studies were by the same group of investigators, Evans et al. ${ }^{5,15,19}$ who examined BSI in VA patients with SCI. The first was a retrospective cohort examining healthcare-associated infections in that population, ${ }^{19}$ another was a multi-center descriptive study of the SCI population, ${ }^{19}$ and the last examined the effect of inadequate initial treatment. ${ }^{15}$ These studies reported a relatively high rate of BSI in this population at 6.0, 7.2 and 10.7 episodes per 100 admissions, with a predominance of bacteremia cases being healthcare-associated infections. An important risk factor was antecedent antimicrobial use and hospitalization. ${ }^{5,15,19}$ Primary BSI were more likely to be undertreated than those secondary to another clear source (that is, urinary), suggesting that primary BSI may be overlooked in this population. The other cohort study in this population found a significantly lower rate of infection $(10 \%)$ in this population. ${ }^{15}$

All three case series reported similar conclusions on the pathogenesis and epidemiology of BSI in SCI; namely that most are secondary to skin/soft tissue tract infections or UTI, and that healthcareassociated organisms were more common than in the non-SCI population. ${ }^{8,9,12}$ Waites et al. also found that relapse and reinfection with BSI were very common in this population. ${ }^{6}$ Wall et al. ${ }^{12}$ reported that $15 \%$ of the BSIs were related to intravascular catheters. Interestingly, one study by Montgomerie et al. ${ }^{9}$ found that inadequate and delayed therapy for BSI was not a significant predictor of poor outcome. No other study addressed this question.

Overall, these data suggest that BSIs may be under-recognized, and that a thorough source evaluation is indicated in these patients because this is most likely to be secondary to another infection.

\section{Urinary tract infections}

The largest group of studies was UTIs, with a total of 25 reporting on UTI-related outcomes. ${ }^{5,20-43}$ All of these studies focused on patients with urinary catheters, either intermittent catheterization or chronic indwelling devices. All included studies used similar definitions for UTIs, combining culture, urinalysis and symptoms (for example, fever) to identify definitive UTI cases. Studies attempting to assess the prevalence of UTIs across SCI patients found infection rates ranging from 10 to $68 \%$ post-SCI. ${ }^{5,20,22,24,30,32,37,40,44}$ Four studies identified

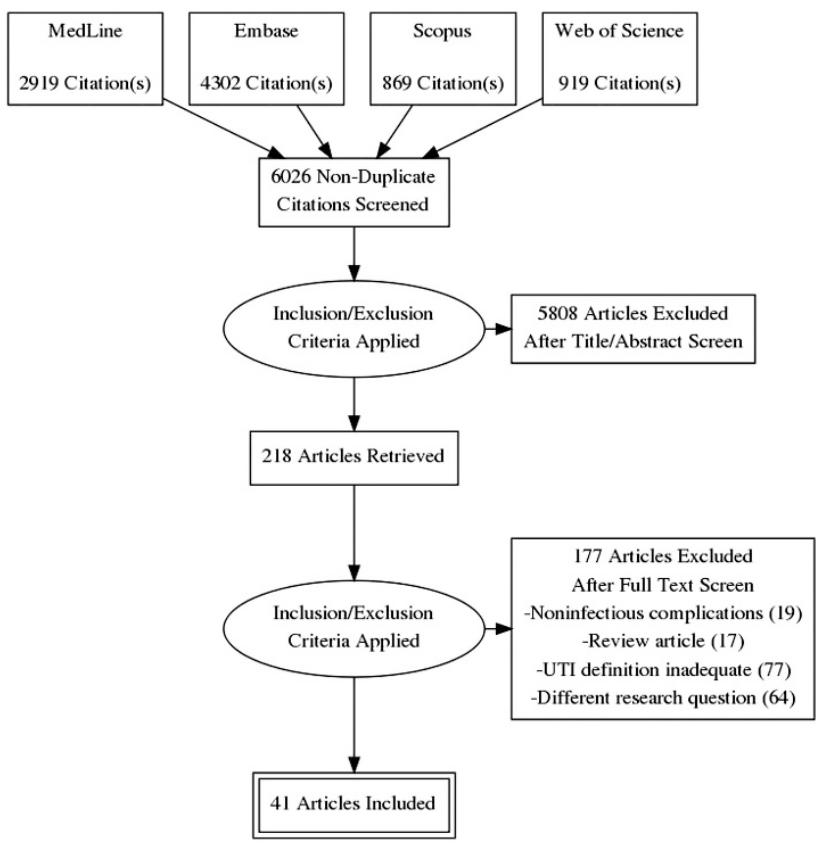

Figure 1 PRISMA flow diagram of included studies. 
Table 1 Bloodstream infections

\begin{tabular}{|c|c|c|c|c|c|c|}
\hline Study & Design & Population & $\mathrm{N}$ & Incidence & Microbiology/major pathogens & Major conclusions \\
\hline Bhatt et al. ${ }^{18}$ & $\begin{array}{l}\text { Retrospective } \\
\text { cohort }\end{array}$ & $\begin{array}{c}\text { VA SCI } \\
\text { inpatients }\end{array}$ & 3136 & $1.3 \%$ & $\begin{array}{c}\text { CONS }(36.6 \%) \\
\text { S. aureus }(12.2 \%) \\
\text { E. coli }(12.2 \%) \\
\text { P. mirabilis }(9.8 \%) \\
\text { S. marcescens }(9.8 \%)\end{array}$ & $\begin{array}{l}\text { 17\% mortality; not significantly different bacter- } \\
\text { iology compared with non-SCl reports }\end{array}$ \\
\hline Montgomerie et al. ${ }^{9}$ & Case series & $\begin{array}{l}\text { Inpatients } \\
\text { with } \mathrm{SCl} \text { and } \\
\text { bacteremia }\end{array}$ & 93 & $\mathrm{~N} / \mathrm{A}$ & $\begin{array}{l}\text { Varied by primary source; UTI associated } \\
\text { were } E \text {. coli and enterococci predominant, } \\
\text { skin/soft tissue anaerobe } \\
\text { predominant, and no clear predominant } \\
\text { species in pneumonia or primary BSIs }\end{array}$ & $\begin{array}{c}\text { No increase in mortality or severity of illness with } \\
\text { delayed therapy }\end{array}$ \\
\hline Waites et al. ${ }^{8}$ & Case series & $\begin{array}{l}\text { Inpatients } \\
\text { with } \mathrm{SCl} \text { and } \\
\text { bacteremia }\end{array}$ & 30 & $\mathrm{~N} / \mathrm{A}$ & $\begin{array}{c}\text { CONS (38.1) } \\
\text { S. aureus }(16.3 \%) \\
\text { Klebsiella spp. (12.7\%) }\end{array}$ & $\begin{array}{c}\text { UTI most frequent site of original BSI, followed by } \\
\text { pressure ulcers and respiratory tract. Reinfection } \\
\text { and relapse very common. }\end{array}$ \\
\hline Wall et al. ${ }^{12}$ & Case series & $\begin{array}{l}\text { VA SCI } \\
\text { inpatients }\end{array}$ & 1664 & $5.8 \%$ & $\begin{array}{c}\text { Varied by primary source; higher prevalence } \\
\text { of MRSA across all sources }\end{array}$ & $\begin{array}{l}\text { Most associated with pressure ulcers or indwelling } \\
\text { urinary catheters; malnourishment significant pre- } \\
\text { dictor of outcome }\end{array}$ \\
\hline Evans et al. ${ }^{5}$ & $\begin{array}{l}\text { Retrospective } \\
\text { cohort }\end{array}$ & $\begin{array}{c}\text { VA SCI } \\
\text { inpatients }\end{array}$ & 226 & $\begin{array}{c}16.9 \% \\
6.0 / 1000 \\
\text { patient days }\end{array}$ & $\begin{array}{l}\text { S. aureus (96 isolates (18.9\%)) } \\
\text { Other Staphylococcus species (72 (14.2\%)) } \\
\text { Untyped Gram-negative bacilli (54 (10.6\%)) }\end{array}$ & $\begin{array}{l}\text { Majority cases were healthcare associated and had } \\
\text { antecedent antimicrobial use }\end{array}$ \\
\hline Evans et al. ${ }^{19}$ & $\begin{array}{l}\text { Retrospective } \\
\text { cohort }\end{array}$ & $\begin{array}{l}\text { VA SCI } \\
\text { inpatients }\end{array}$ & 5699 & $\begin{array}{c}7.2 \mathrm{BSI} / \\
100 \\
\text { admissions }\end{array}$ & $\begin{array}{c}\text { S. aureus }(34.4 \%) \\
\text { Enterococcus faceium }(14.0 \%) \\
\text { E. coli }(12.6 \%)\end{array}$ & $\begin{array}{c}\text { Majority cases were healthcare associated and had } \\
\text { antecedent antimicrobial use }\end{array}$ \\
\hline Evans et al. ${ }^{15}$ & $\begin{array}{l}\text { Retrospective } \\
\text { cohort }\end{array}$ & $\begin{array}{l}\text { VA SCI } \\
\text { inpatients }\end{array}$ & 2202 & $\begin{array}{l}10.7 \mathrm{BSI} / \\
100 \\
\text { admissions }\end{array}$ & $\begin{array}{l}\text { S. aureus }(36.6 \%) \text {, E. faecium }(15.3 \%) \text {, } \\
\text { E. coli }(14.9 \%) \text {, P. aeruginosa }(12.3 \%)\end{array}$ & $\begin{array}{l}\text { Majority cases were healthcare associated and had } \\
\text { antecedent antimicrobial use }\end{array}$ \\
\hline
\end{tabular}

Abbreviations: BSI, bloodstream infection; CONS, coagulase negative Staphylococci; SCI, spinal cord injury, UTI, urinary tract infection; VA, veteran's administration.

UTI as the most common secondary condition affecting patients with SCI. $5,24,37,44$ A study restricted to patients with SCI and fever found that UTI was commonly associated with coinfections such as infected decubitus ulcers, and osteomyelitis, but less common as a single source of infection. ${ }^{43}$

Diagnosis of UTI in SCI patients is challenging, as typical symptoms may not be detectable due to neurologic injury. One study found that patient self-diagnosis was only $48 \%$ sensitive and $71 \%$ specific for UTI, and those specific individual symptoms such as cloudy urine or foul smell showed poor sensitivity and specificity. The most sensitive objective sign of UTI was pyuria at $83 \%$, whereas fever was $99 \%$ specific in this cohort. Overall, this suggested that clinical assessment considering all available data and symptoms was the most accurate way to diagnose UTI, and relying on any single symptom or finding is unreliable. ${ }^{28}$ Given the frequent lack of localizing symptoms in SCI patients, it is essential to consider and clinically evaluate all alternative sources before attributing a fever to UTI.

One study examined the impact of different bladder management strategies on the frequency of UTIs. Overall, there was no statistically significant difference observed between indwelling and clean intermittent catheterization, with 3 and 2 infections per year, respectively. ${ }^{23}$ This may owe, in part, to patient selection factors or the relatively small number of patients with indwelling catheters. A summary of rates of infection with different strategies for bladder management is provided in Table 2.

Two studies examined the catheter material as a potential route for preventing catheter-associated urinary tract infection in SCI patients. Hydrophilic catheters become slippery when soaked in water, allowing for insertion with fewer traumas and without the need for lubrication, which can reduce potential contamination and infection. The first study, restricted to male patients with acute SCI, found a significant decrease in the rates of symptomatic UTI when using hydrophilic catheters. ${ }^{33}$ The second study started with 224 patients randomized to hydrophilic and non-hydrophilic catheters, but lost half to follow-up due to study withdrawals and changes in bladder management strategies. Nonetheless, they did find longer time to first UTI with hydrophilic catheters and fewer catheter-associated urinary tract infections while hospitalized. Overall rates of infection by the end of the study remained similar. ${ }^{26}$

Maynard and Diokno examined the effect of antibacterial prophylaxis on rates of significant bacteriuria and clinical infection in recent traumatic SCI patients. Prophylaxis was with trimethoprim/sulfamethoxazole or nitrofurantoin in the case of sulfamethoxazole allergy. Patients were randomized to prophylaxis or no prophylaxis, and treatment of significant bacteriuria versus clinical UTI-only arms. No significant differences were noted across groups, though there was a trend toward more UTIs in the no-prophylaxis/treating clinical UTI-only subgroup. ${ }^{42}$ Biering-Sorensen et al. examined low-dose ciprofloxacin as prophylaxis for UTI in SCI patients. In a yearlong study of 21 patients in a randomized, placebo-controlled, crossover study, they found a significant drop in symptomatic UTI, from 59 in the placebo arm to 5 in the ciprofloxacin period. However, they also noted that one patient developed colonization with a ciprofloxacinresistant Acinetobacter spp. during the treatment period. ${ }^{38}$ Another study by Gribble et al. examined using low-dose trimethoprim/ sulfamethoxazole ( $40 \mathrm{mg}$ per $200 \mathrm{mg}$ ) once daily for prophylaxis that the rate of UTI was reduced significantly in the prophylaxis arm, but they also noted side effects that required discontinuation of the drug in $10 \%$ of the treatment arm. Further, 3 years into the study, trimethoprim/sulfamethoxazole-resistant isolates were 
Table 2 Summary of bladder management strategies

\begin{tabular}{|c|c|c|c|c|}
\hline Study & Bladder management & $\mathrm{N}$ & UTI frequency & $\%$ \\
\hline \multirow{2}{*}{ Afsar et al. ${ }^{23}$} & Clean intermittent catheter & 104 & 2 per year & 67.6 \\
\hline & Normal voiding & 19 & 0 per year & 0 \\
\hline \multirow[t]{2}{*}{ Togan et al. ${ }^{20}$} & IC & 57 & & 59.6 \\
\hline & Clean intermittent catheter & 24 & & 16.7 \\
\hline \multirow{4}{*}{ Singh et al. ${ }^{25}$} & Condon drainage & 45 & $0.34 / 100$ person-day & \\
\hline & Suprapubic cystostomy & 24 & $0.56 / 100$ person-day & \\
\hline & Reflex voiding & 32 & $0.34 / 100$ person-day & \\
\hline & Normal voiding & 40 & $0.32 / 100$ person-day & \\
\hline \multirow[t]{2}{*}{ Menon and $\operatorname{Tan}^{40}$} & IC & 43 & 4 patient per stay $(2-6)$ & \\
\hline & Voiding with/without intermittent catheterization & 12 & 1 patient per stay (0-3) & \\
\hline
\end{tabular}

Abbreviations: IC, indwelling catheter; UTI, urinary tract infection.

more frequent. ${ }^{39}$ The only recent study, a retrospective study by Ployptech et al., found a high rate of resistance to commonly used prophylactic regimens, and advocated that use of this be restricted to exceptionally high-risk patients, such as those with vesicoureteral reflux and elevated detrusor storage phase, guided by pathogens isolated in that particular patient. ${ }^{22}$

One study examined the effect of daily $500 \mathrm{mg}$ cranberry extract tablets in reducing UTI in this population. In a randomized crossover study of 47 patients, one-third as many UTIs were observed in those taking cranberry tablets versus placebo. The authors noted in subgroup analysis that good renal function was positively associated with increased efficacy of the cranberry tablets. However, the authors also noted that although symptoms were reduced, urinary $\mathrm{pH}$ and flora remained largely unchanged. This was contrary to both of the commonly suggested mechanisms of cranberries, acidification via benzoic/hippuric acid versus inhibition of $E$. coli virulence and adhesion factors. ${ }^{29}$

Darouiche et al. described a novel approach to prophylaxis with competitive bacterial interference. In a randomized trial of 27 subjects, the investigators instilled either sterile saline control or nonpathogenic E. coli 83972 . At 1 year, colonization by the nonpathogenic E. coli appeared to have cut the rate of symptomatic UTI in half. ${ }^{34}$ However, there have been no follow-up studies on this approach in the intervening decade.

Salomon et al. reported on the use of a weekly oral cyclic antibiotic program, where SCI patients were given one of the following antibiotics weekly for over 2 years: amoxicillin, cefixime, fosfomycin, nitrofurantoin or trimethoprim/sulfamethoxazole. In an initial study of 38 patients, symptomatic UTI episodes were significantly reduced from 9.4 episodes yearly to 1.8 episodes yearly, with concomitant reductions in total antibiotic use and hospitalizations. ${ }^{31}$ A follow-up study in six pregnant women with SCI found a similar benefit. ${ }^{27}$

Three studies evaluated the duration of treatment for predicting relapse in UTI patients; the first study randomized patients to either six or fourteen days of ciprofloxacin. Although initial cure was similar between groups, shorter treatment conferred a greater risk of relapse, even with sensitive organisms. ${ }^{36}$ The same study group did another follow-up in 2004 with similar results. ${ }^{35}$ The third study randomized patients to 5 or 10 days in 2014, with antimicrobials guided by gram stain. When used in conjunction with catheter exchange, rates of initial cure were similar. The authors note this differs from the previous study, and may be in part associated with the targeted antimicrobial protocol and the decision to exchange catheters routinely as part of treatment. ${ }^{21}$

One older study evaluated prostatitis as opposed to other, more traditional UTIs. In a small study of six patients with SCI and prostatitis, long-term antibiotics were able to achieve cure in only one patient. The authors attributed this to poor antibiotic penetration of prostatic fluid and high prevalence of $P$. aeruginosa as a causative organism in their cohort. ${ }^{41}$

Overall, prophylaxis papers described a variety of preventive strategies, but none that were consistently superior. More research is needed to determine which prophylactic agents and practices would be most beneficial, especially with emerging resistance and changes in microbiology over time. Longer duration of antimicrobial therapy for established UTI episodes, however, appears to reduce the likelihood of relapse or treatment failure.

\section{Pneumonia}

Five studies that addressed pneumonia were identified, including three retrospective cohort studies, ${ }^{45}$ a retrospective case series ${ }^{46}$ and one prospective study. ${ }^{43}$ All were in adult populations, and four were in VA patient populations. ${ }^{45-47}$

Sugarman et al. conducted both a prospective and retrospective cohort analysis of SCI patients with fever. Pneumonia was found to be relatively rare in this study, with no definite cases in the prospective cohort $(n=72)$ and four cases in the retrospective cohort $(n=56)$. Overall, other causes appeared to predominate as sources of fever and infection in this population. ${ }^{43}$

Burns et al. described the treatment of community-acquired pneumonia (CAP) in SCI patients in a retrospective case series of 41 patients. They noted a relatively low rate of 'classic' pneumonia presentations (for example, fevers, cough and radiologic correlate) compared with that in the general population, though no particular sign or symptom was of better use. In this study, guideline-adherent therapy and appropriate microbiologic evaluation were relatively low. Although short-term mortality was similar to the general CAP population, hospital length of stay was considerably longer (mean 19.7 days) 
in SCI patients. Two cases required intubation. Overall, the authors concluded that although the course and outcomes of CAP are not significantly different in SCI patients, the difficulties in recognizing pneumonia in a timely manner in these patients make it critical to ensure adequate preventive measures, such as vaccination for influenza and pneumonia. Only five patients had organisms recovered for identification (Table 3). ${ }^{46}$

Chang et al. conducted a retrospective cohort study on 260 SCI patients with pneumonia admitted to a VA hospital between 1998 and 2000. No difference was found in mortality (overall rate $8.5 \%$ ), but increased length of stay was observed in SCI cases. Microbiology showed a predominance of Streptococcus pneumoniae again, but also a high prevalence of Pseudomonas (Table 4). ${ }^{45}$

Evans et al. examined the proportion of SCI patients with CAP receiving guideline-adherent care. Evans noted an improvement relative to what was observed in the earlier Burns et al. study, though still observed suboptimal timing for antibiotic delivery and adherence to microbiologic testing guidelines. The challenges of timely recognition of pneumonia in this population were again cited as a potential barrier to care, and the importance of prevention was highlighted. However, this study also noted that vaccination rates for pneumococcal pneumonia and influenza were quite high in this population. ${ }^{47}$

Taken together, these data seem to suggest that the approach to pneumonia in the SCI patient does not differ significantly from the general patient population. The higher prevalence of Pseudomonas spp. was not consistent across studies.

\section{Skin and soft tissue infections}

Two studies examined significant complications associated with infected decubiti. Sugarman et al. found a high rate of complicated osteomyelitis in those with infected decubitus ulcers, exceeding 50\%. Most patients with skin and soft tissue infections had multiple foci of infection. ${ }^{43}$ Backhaus et al. evaluated a link between Fournier's gangrene and antecedent pressure ulcers in a retrospective study. In 16 cases of confirmed Fournier's in SCI patients, $81 \%$ were determined to have originated from a pressure ulcer with polymicrobial infection. ${ }^{48}$

Heym et al. conducted a bacteriological study of infected decubiti using 77 patients with deep-tissue specimens obtained during debridement surgery, as well as superficial swabs and drainage specimens. Drainage and deep tissue showed a poor overall correlation with the high-quality surgical samples, and surgical samples showed no growth in $10 \%$ of clinically infected cases, $1-2$ organisms in $69 \%$, and 3 or more in $21 \%$. The most frequently recovered organisms were Enterobacteriaceae group, accounting for $29 \%$ of isolates (predominantly E. coli and P. mirabilis), followed by Staphylococcus spp. at $28 \%$ (mostly S. aureus), then Streptococci/enterococci at $26 \%$ (predominantly Enterococcus faecalis) and other gram negatives at $10 \% .{ }^{49}$

Maeder et al. reported their experience with a decolonization protocol to prevent MRSA-associated wound infections and pressure ulcers. Patients were prospectively tested for MRSA colonization in the nares, throat, perineum, urine and wounds. Patients hospitalized for pressure ulcer management had MRSA colonization of the nares $49 \%$ of the time, but wound colonization $94 \%$ of the time. Among other SCIs, the nares were the most frequently colonized site (72\%). Maeder implemented a standard protocol using MRSA, screening, isolation and 7-10-day courses of systemic novobiocin, trimethoprim/ sulfamethoxazole or rifampin with topical antimicrobials applied to the nares and any wounds. This protocol was associated with both successful decolonization and reduced readmission. ${ }^{50}$
These data suggest that decubiti in the SCI population are prone to infection with resistant organisms, and strategies for effective pressure ulcer prevention and treatment are critical to optimal care.

\section{DISCUSSION}

Care of the SCI patient is complex, and likely to become more frequent in coming years due to improvement in acute care leading to increased survival of initial injury and prolonged life expectancy. The evidence base for infection prevention and treatment in this population is not robust, and will need to grow to provide high-quality evidence-based recommendations.

Our findings suggest that BSI primarily arises as a secondary phenomenon from the UTI, ${ }^{8}$ skin/soft tissue infections and intravascular catheter infections. ${ }^{12}$ Two recent studies have demonstrated that intravascular infections, in particular, were overlooked and are associated with delayed treatment and poor outcomes. ${ }^{15,19}$ This trend was not observed in two early studies. This is likely related to changing trends in the concepts of early antibiotic therapy and antibiotic resistance patterns. ${ }^{9,18}$ Efforts to optimize the treatment of BSI in the SCI population are needed. However, the studies of BSIs were almost exclusively in males and in the VA population, and therefore these findings may not be generalizable to all patients and settings. Analyses that include general population may help to clarify this further.

Pneumonias in SCI patients tended to be due to typical organisms associated with CAP. ${ }^{45,46}$ However, it is worth noting that symptoms of pneumonia may be more subtle in this population. Patients with SCI may present with weaker cough and consequently poor pulmonary hygiene, which could delay recognition, and conceivably delay recovery. Chang et al. ${ }^{45}$ showed a higher than expected rate of respiratory Pseudomonas cultures in this population. However, it is unclear whether this simply represents higher colonization rate of lower airways or more frequent healthcare-associated pneumonias or both. Further investigation is needed to determine whether empiric regimens should include anti-Pseudomonas coverage in a larger proportion of the SCI population.

In a study excluded from this review because of inclusion of non-SCI patients, tracheal plugging and pneumonia were strongly associated with positioning and mobility. Supine patients were at higher risk than patients seated $\leqslant 5$ times per week, who in turn were at lower risk than those seated $\geqslant 6$ days per week. ${ }^{51}$ This is broadly consistent with what has been observed with early mobilization of intensive care unit patients and risk of pneumonia. ${ }^{52}$ Mobilizing the SCI patient can be difficult, but this suggests it may be a promising area for research into pneumonia prevention in this population.

A notable omission in the available literature includes the number of patients who were receiving respiratory therapy or support at the time they developed their pneumonias. There is a gap in the literature regarding modalities and routes of mechanical ventilation, and strategies for respiratory toilet that may be associated with less pneumonia.

By far the most studied infections in SCI patients are UTIs. Most studies used similar definitions for UTIs, combining culture, urinalysis and symptoms (for example, fever) ${ }^{40}$ to identify definitive UTI with rates as high at $68 \% .{ }^{37}$ Evidence suggests that UTIs are very frequent and usually more severe in SCI patients than in the general population..$^{20,24,37,44}$ However, differentiating active infection from asymptomatic bacteriuria is quite challenging considering the lack of classic symptomatology in SCI patients, high frequency of other sources of infection ${ }^{43}$ and increased rates of asymptomatic colonization. There was not a clear trend toward any particular organism or group of organisms being consistently responsible for UTI in this 
Table 3 Urinary tract infections

\begin{tabular}{|c|c|c|c|c|c|c|}
\hline Study & Design & Population & N & UTI incidence & Microbiology/major pathogens & Major conclusions \\
\hline $\begin{array}{l}\text { Maynard and } \\
\text { Diokno }^{42}\end{array}$ & Prospective trial & $\begin{array}{l}\text { Recent traumatic SCI } \\
\text { inpatient }\end{array}$ & 50 & $26 \%$ & NR & $\begin{array}{l}\text { Antibacterial prophylaxis } \\
\text { decreased significant bacter- } \\
\text { iuria, but not clinical infection }\end{array}$ \\
\hline Gribble et al. ${ }^{39}$ & $\begin{array}{l}\text { Prospective ran- } \\
\text { domized control } \\
\text { trial }\end{array}$ & $\begin{array}{l}\text { Inpatients with recent } \\
\qquad \mathrm{SCl}\end{array}$ & 129 & $N / A$ & $\begin{array}{l}\text { In the placebo group } \\
\text { CONS }(30 \%) \text { K. pneumoniae }(9 \%) \text {, } \\
\text { E. coli }(8 \%) \text {, Gram-positive bacilli } \\
(14 \%) \text { Enterobacter spp. }(4 \%)\end{array}$ & $\begin{array}{c}\text { Low-dose TMP-SMX reduced the } \\
\text { risk of UTI, but had increased } \\
\text { adverse events }\end{array}$ \\
\hline Dow et al. ${ }^{35}$ & $\begin{array}{l}\text { Prospective ran- } \\
\text { domized control } \\
\text { trial }\end{array}$ & $\begin{array}{l}\text { SCl outpatients with } \\
\text { symptomatic UTI }\end{array}$ & 60 & $N / A$ & $\begin{array}{c}\text { Klebsiella spp. (30\%), Enterococ- } \\
\text { cus spp. }(22 \%) \\
\text { E. coli }(22 \%), \text { Pseudomonas (7\%) } \\
\text { Acinetobacter spp. (10\%), } \\
\text { Proteus spp. (7\%), Staphylococcus } \\
\text { spp. (16\%) }\end{array}$ & Most $(62 \%)$ were monomicrobial \\
\hline Girard et al. ${ }^{32}$ & $\begin{array}{l}\text { Nationwide preva- } \\
\text { lence studies }\end{array}$ & $\begin{array}{l}\text { Rehabilitation unit } \\
\text { patients with } \mathrm{SCl}\end{array}$ & 78 & $10 \%$ & $\begin{array}{c}\text { E. coli }(22 \%), \text { K. pneumoniae } \\
(22 \%), \\
\text { S. aureus, Enterobacter aerogenes, } \\
\text { candida spp. Enterococcus spp. } \\
(11 \% \text { each) }\end{array}$ & $\begin{array}{l}\text { Indwelling urinary catheters } \\
\text { were independently associated } \\
\text { with higher risk of SCl }\end{array}$ \\
\hline Singh et al. ${ }^{25}$ & $\begin{array}{l}\text { Prospective } \\
\text { cohort }\end{array}$ & $\begin{array}{l}\text { At least } \mathrm{C} 4 \text { level } \mathrm{SCl} \\
\text { with bladder } \\
\text { symptoms }\end{array}$ & 545 & $\begin{array}{l}0.64 \text { UTI/100 } \\
\text { person-days }\end{array}$ & $\begin{array}{c}\text { E. coli }(16.5 \%) \\
\text { Klebsiella }(12 \%) \\
\text { Staphylococcus aureus (8\%), } \\
\text { P. aeruginosa (8\%). (polymicrobial) }\end{array}$ & $\begin{array}{l}\text { Most of the time the organisms } \\
\text { had more than one isolate }\end{array}$ \\
\hline Adriaansen et al. ${ }^{24}$ & $\begin{array}{l}\text { Prospective longi- } \\
\text { tudinal study }\end{array}$ & $\begin{array}{c}\text { Wheelchair- } \\
\text { dependent adults } \\
\text { with SCI, both in and } \\
\text { outpatient }\end{array}$ & 139 & $\begin{array}{l}56.5 \% \text { at } 1 \text { year, } \\
58.3 \text { at } 2 \text { years, } \\
58.9 \% \text { at } 5 \text { years }\end{array}$ & NR & $\begin{array}{l}\text { UTI was the most common } \\
\text { complication of SCl }\end{array}$ \\
\hline Afsar et al. ${ }^{23}$ & $\begin{array}{l}\text { Prospective } \\
\text { cohort }\end{array}$ & $\begin{array}{l}\text { New } \mathrm{SCl} \text { inpatients } \\
\text { being followed for } \\
\text { bladder management }\end{array}$ & 164 & NR & NR & $\begin{array}{l}\text { No difference in overall rates of } \\
\text { UTIs in indwelling versus clean } \\
\text { intermittent catheterization }\end{array}$ \\
\hline Ploypetch et al. ${ }^{22}$ & $\begin{array}{l}\text { Retrospective } \\
\text { review }\end{array}$ & $\begin{array}{l}\mathrm{SCl} \text { patients admitted } \\
\text { to rehabilitation ward }\end{array}$ & 100 & $\begin{array}{l}45 \text { patients had } \\
57 \text { episodes of } \\
\text { UTI }\end{array}$ & $\begin{array}{l}\text { E. coli }(50 \%) \\
\text { Pseudomonas }(17.3 \%) \\
\text { E. facialis }(7 \%)\end{array}$ & \\
\hline Togan et al. ${ }^{20}$ & $\begin{array}{l}\text { Prospective } \\
\text { cohort }\end{array}$ & $\begin{array}{l}\mathrm{SCl} \text { patients followed } \\
\text { at rehabilitation }\end{array}$ & 93 & $23 \%$ & $\begin{array}{c}\text { E. coli (42\%), Klebsiella spp. } \\
\text { (21\%), Enterococcus spp. (8.3\%), } \\
\text { Pseudomonas spp. (8\%) }\end{array}$ & $\begin{array}{l}\text { E. coli is the most common } \\
\text { cause of UTI, and was asso- } \\
\text { ciated with urinary } \\
\text { catheterization }\end{array}$ \\
\hline
\end{tabular}

Abbreviations: CONS, coagulase negative staphylococci; HAI, healthcare-associated infections; NR, not reported; SCI, spinal cord injury; UTI, urinary tract infection. 
Table 4 Pneumonia

\begin{tabular}{ll}
\hline Study name & Microbiology (n isolated) \\
\hline Burns et al. ${ }^{46}$ & Organism identified in 5 cases (12.2\% of all cases.) \\
& -Streptococcus pneumonia (2) \\
& -Haemophilus influenza (1) \\
& -Gram-negative rods (2) \\
Chang et al. ${ }^{45}$ & Organism identified in 62 cases \\
& -Streptococcus pneumoniae (20) \\
& -Pseudomonas spp. (13) \\
& -Haemophilus influenza (6) \\
& - Klebsiella spp. (5) \\
& -Streptococcus group A (3) \\
& -Streptococcus group B (3) \\
& -Streptococcus, other (2) \\
& -Escherichia coli (1) \\
-Other organism (9)
\end{tabular}

Summary of microbiology reported in pneumonias.

population, with several studies reporting monomicrobial infections, and others reporting high rates of mixed infections. Data regarding impact of catheterization strategies on the rates of UTI are variable, with some studies reporting a strong relationship with catheter use, ${ }^{20,32}$ and others showing no real difference between an indwelling urinary catheter and intermittent catheterization. ${ }^{23}$ This may in part be due to the difficulty in making a correct diagnosis of symptomatic UTI in this population.

Many investigators have explored the idea of decreasing infection rates using different prophylactic strategies. Prophylaxis was not universally successful, and some reported high rates of adverse events and concomitant development of antimicrobial resistance. ${ }^{39}$ There was a decrease in rates of asymptomatic bacteriuria noted in some studies, but symptomatic infection rates were generally not changed. ${ }^{42}$ These results are consistent with a recent meta-analysis by Morton et al. ${ }^{53}$ which found limited support for routine prophylaxis. It should be noted that Morton's analysis accepted definitions of UTI limited to bacteriuria, and the present review has restricted itself to studies that describe symptomatic UTIs only. One study found that regression of pyuria was a sensitive and specific indicator for appropriate therapy for symptomatic UTI in patients undergoing intermittent urinary catheterization. ${ }^{54}$ Weekly oral cyclic antibiotics appear promising as a prevention strategy for UTIs, ${ }^{27,31}$ though more robust data are needed to make a strong recommendation for their routine use.

We restricted our analysis of UTIs to symptomatic infections in accordance with IDSA guidelines, and published data supporting the idea that asymptomatic bacteriuria is of no consequence. ${ }^{55,56}$ However, relapsing episodes of asymptomatic bacteriuria in SCI patients were associated with developing symptomatic UTI in one study. ${ }^{57}$ This is further complicated by poor symptom assessment in this population, though clinical evaluation and laboratory findings remain useful in diagnosing true UTI in SCI patients. ${ }^{28}$ Moreover, these results are tempered by the heterogeneity of the studies available for review. Most of the studies had small samples, were retrospective and used variable definitions of UTIs. Also, more elaborate statistical analysis was not possible owing to different indexes utilized for reporting (examples are UTI per years versus UTI per person-days). Finally, outcomes may differ due to the secular trends in prevention, recognition and treatment of UTIs over the last two decades.
Skin and soft tissue infections are another major area of concern for this patient population. Humidity, friction and shear forces on immobilized patients are the perfect milieu for skin breakdown. Superficial colonization of wounds and true infections of skin ulcer are difficult to differentiate. ${ }^{58}$ Anson and Shepherd ${ }^{59}$ reported a prevalence of pressure ulcers in SCI patients as high as $32.4 \%$, with greater frequency in those whose injury was less recent compared with those having acute SCI. The risk of infection is proportional to the stage of the ulcer, ${ }^{59}$ and it has been suggested that wounds may need to be screened for MRSA and other multidrug-resistant organisms separately from nares in SCI population. ${ }^{50}$ The VA's MRSA prevention initiative guidelines for SCI centers includes a recommendation for swabbing and screening pressure ulcers for MRSA. ${ }^{60}$ On the basis of published data, screening and decolonization for MRSA seems reasonable in SCI patients. However, antimicrobial therapy for deeper infections (for example, osteomyelitis) should be guided by cultures obtained during surgical procedures.

Many of the research studies described are plagued with limitations such as small sample size, lack of distinction between acute and chronically injured SCI patients or healthcare versus communityacquired infections. Future studies should include larger study samples and clarity and distinction of epidemiological characteristics of the sample and infections. Moreover, better data are needed for both prevention and management questions. Prevention strategies may include proper technique of insertion of urinary catheters and management of long-term use of these catheters. High rate of colonization and infection with resistant organisms, longer lengths of hospital stay and strategies to prevent spread of these resistant organisms in the environment are other areas of potential research in this patient population.

An important limitation to our results was the lack of a restriction on publication dates. We did this to capture the fullest extent of pertinent literature in these topics, and restricted to studies using infection definitions compatible with modern practice to increase relevance. However, this does mean that emerging resistance over the past 30 years may impact the applicability of the findings of older studies. Newer studies are needed reflecting the potential changing epidemiology in more recent years.

\section{CONCLUSION}

We found that there is a paucity of data on prevention and management of infections in SCI patients, especially in recent years. Methodologically sound studies are needed to better address optimal management of active infections as well as timing and duration of prophylaxis for UTI in SCI patients. Such studies will add to the evidence base necessary for effective prevention and management interventions that improve outcomes in SCI patients.

On the basis of the limited available evidence, we do not find sufficient evidence of any prophylactic strategies to reduce bloodstream, respiratory or skin and soft tissue infection. UTIs may be preventable through good catheter management practices; antibiotic prophylaxis may work, but the risk of selecting for resistant isolates and inconsistent outcomes limit the long-term utility of this approach.

Management of infections of SCI patients must rely first on a high index of suspicion and thorough evaluation. BSI, in particular, should prompt a thorough evaluation for sources, but clinicians should consider a broad differential given the atypical presentations of infections in SCI patients. Early empiric treatment and thorough source evaluation and control are the cornerstones of good SCI infection management. 


\section{DATA ARCHIVING}

There were no data to deposit.

\section{CONFLICT OF INTEREST}

The authors declare no conflict of interest.

\section{ACKNOWLEDGEMENTS}

JCO is supported in part by the Mayo Clinic Robert D. and Patricia E. Kern Center for the Science of Health Care Delivery. NS is supported by a VA patient safety center and VA MERIT grant. CTE is supported by the Presidential Early Career Award for Scientists and Engineers (USA 12-564).

1 Wyndaele M, Wyndaele J-J. Incidence, prevalence and epidemiology of spinal cord injury: what learns a worldwide literature survey? Spinal Cord 2006; 44: 523-529.

2 Blair JA, Patzkowski JC, Schoenfeld AJ, Rivera JDC, Grenier ES, Lehman RA et al. Spinal column injuries among Americans in the global war on terrorism. J Bone Joint Surg 2012; 94: e135 1-e135 9.

3 National Spinal Cord Injury Statistical Center. Spinal cord injury. Facts and figures at a glance Birmingham. University of Alabama at Birmingham: AL. 2016. Available from https://www.nscisc.uab.edu/.

4 Montgomerie JZ. Infections in patients with spinal cord injuries. Clin Infect Dis 1997; 25: 1285-1290 quiz 91-2.

5 Evans CT, LaVela SL, Weaver FM, Priebe M, Sandford P, Niemiec P et al. Epidemiology of hospital-acquired infections in veterans with spinal cord injury and disorder. Infect Control Hosp Epidemiol 2008; 29: 234-242.

6 Evans CT, LaVela SL, Weaver FM, Priebe M, Sandford P, Niemiec P et al. Epidemiology of hospital-acquired infections in veterans with spinal cord injury and disorder. Epidemiology 2008; 29: 234-242.

7 Cardenas DD, Hoffman JM, Kirshblum S, McKinley W. Etiology and incidence of rehospitalization after traumatic spinal cord injury: a multicenter analysis. Arch Phys Med Rehabil 2004; 85: 1757-1763.

8 Waites KB, Canupp KC, Chen Y, DeVivo MJ, Moser SA. Bacteremia after spinal cord injury in initial versus subsequent hospitalizations. J Spinal Cord Med 2001; 24 96-100.

9 Montgomerie JZ, Chan E, Gilmore DS, Canawati HN, Sapico FL. Low mortality among patients with spinal cord injury and bacteremia. Rev Infect Dis 1991; 13: 867-871.

10 De Vivo MJ, Stuart Krause J, Lammertse DP. Recent trends in mortality and causes of death among persons with spinal cord injury. Arch Phys Med Rehabil 1999; 80: 1411-1419.

11 Michael J, Krause JS, Lammertse DP. Recent trends in mortality and causes of death among persons with spinal cord injury. Arch Phys Med Rehabil 1999; 80: 1411-1419.

12 Wall BM, Mangold T, Huch KM, Corbett C, Cooke CR. Bacteremia in the chronic spina cord injury population: risk factors for mortality. J Spinal Cord Med 2003; 26 248-253.

13 Frankel H, Coll J, Charlifue S, Whiteneck G, Gardner B, Jamous M et al. Long-term survival in spinal cord injury: a fifty year investigation. Spinal Cord 1998; 36: 266-274.

14 Hsiao CY, Yang HY, Hsiao MC, Hung PH, Wang MC. Risk factors for development of acute kidney injury in patients with urinary tract infection. PLOS ONE 2015; 10 e0133835.

15 Evans CT, Burns SP, Chin A, Weaver FM, Hershow RC. Predictors and outcomes of antibiotic adequacy for bloodstream infections in veterans with spinal cord injury. Arch Phys Med Rehabil 2009; 90: 1364-1370.

16 Eastwood EA, Hagglund KJ, Ragnarsson KT, Gordon WA, Marino RJ. Medical rehabilitation length of stay and outcomes for persons with traumatic spinal cord injury-1990-1997. Arch Phys Med Rehabil 1999; 80: 1457-1463.

17 Centers for Disease Control and Prevention. Bloodstream Infection Event (Central LineAssociated Bloodstream Infection and Non-central line-associated Bloodstream Infection), http://www.cdc.gov/nhsn/pdfs/pscmanual/4psc_clabscurrent.pdf, January 2015.

18 Bhatt K, Cid E, Maiman D. Bacteremia in the spinal cord injury population. J Am Paraplegia Soc 1987; 10: 11-14.

19 Evans CT, Hershow RC, Chin A, Foulis PR, Burns SP, Weaver FM. Bloodstream infections and setting of onset in persons with spinal cord injury and disorder. Spinal Cord 2009; 47: 610-615.

20 Togan T, Kurt Azap O, Durukan E, Arslan H. The prevalence, etiologic agents and risk factors for urinary tract infection among spinal cord injury patients. Jundishapur $J$ Microbiol 2014; 7: e8905.

21 Darouiche RO, Al Mohajer M, Siddiq DM, Minard CG. Short versus long course of antibiotics for catheter-associated urinary tract infections in patients with spinal cord injury: a randomized controlled noninferiority trial. Arch Phys Med Rehabil 2014; 95 290-296.

22 Ploypetch T, Dajpratham P, Assanasen S, Thanakiatpinyo T, Tanvijit P, Karawek J. Epidemiology of urinary tract infection among spinal cord injured patients in rehabilitation ward at Siriraj Hospital. J Med Assoc Thai 2013; 96: 99-106.

23 Afsar SI, Yemisci OU, Cosar SN, Cetin N. Compliance with clean intermittent catheterization in spinal cord injury patients: a long-term follow-up study. Spinal Cord 2013; 51: 645-649.
24 Adriaansen JJ, Post MW, de Groot S, van Asbeck FW, Stolwijk-Swuste JM, Tepper M et al. Secondary health conditions in persons with spinal cord injury: a longitudinal study from one to five years post-discharge. J Rehabil Med 2013; 45: 1016-1022.

25 Singh R, Rohilla RK, Sangwan K, Siwach R, Magu NK, Sangwan SS. Bladder management methods and urological complications in spinal cord injury patients. Indian J 2011; 45: 141-147.

26 Cardenas DD, Moore KN, Dannels-McClure A, Scelza WM, Graves DE, Brooks M et al. Intermittent catheterization with a hydrophilic-coated catheter delays urinary tract infections in acute spinal cord injury: a prospective, randomized, multicenter trial. $P m R$ 2011; 3: 408-417.

27 Salomon J, Schnitzler A, Ville Y, Laffont I, Perronne C, Denys P et al. Prevention of urinary tract infection in six spinal cord-injured pregnant women who gave birth to seven children under a weekly oral cyclic antibiotic program. Int J Infect Dis 2009; 13: 399-402.

28 Massa LM, Hoffman JM, Cardenas DD. Validity, accuracy, and predictive value of urinary tract infection signs and symptoms in individuals with spinal cord injury on intermittent catheterization. I Spinal Cord Med 2009. 32: 568-573.

29 Hess MJ, Hess PE, Sullivan MR, Nee M, Yalla SV. Evaluation of cranberry tablets for the prevention of urinary tract infections in spinal cord injured patients with neurogenic bladder. Spinal Cord 2008; 46: 622-626.

30 Tantisiriwat N, Kittisomprayoonkul W, Sukonthamarn K, Unhasuta C, Suankratay C, Tantisiriwat $\mathrm{W}$ et al. Uropathogens and empiric antibiotics for the treatment of urinary tract infections in spinal cord injured patients at rehabilitation center, Thai Red Cross Society during 2001 to 2005. J Med Assoc Thai 2007; 90: 2482-2486.

31 Salomon J, Denys P, Merle C, Chartier-Kastler E, Perronne C, Gaillard JL et al. Prevention of urinary tract infection in spinal cord-injured patients: safety and efficacy of a weekly oral cyclic antibiotic (WOCA) programme with a 2 year follow-up-an observational prospective study. J Antimicrob Chemother 2006; 57: 784-788.

32 Girard R, Mazoyer MA, Plauchu MM, Rode G. High prevalence of nosocomial infections in rehabilitation units accounted for by urinary tract infections in patients with spinal cord injury. J Hosp Infect 2006; 62: 473-479.

33 De Ridder DJ, Everaert K, Fernandez LG, Valero JV, Duran AB, Abrisqueta ML et al. Intermittent catheterisation with hydrophilic-coated catheters (SpeediCath) reduces the risk of clinical urinary tract infection in spinal cord injured patients: a prospective randomised parallel comparative trial. Eur Urol 2005; 48: 991-995.

34 Darouiche RO, Thornby JI, Cerra-Stewart C, Donovan WH, Hull RA. Bacterial interference for prevention of urinary tract infection: a prospective, randomized, placebo-controlled, double-blind pilot trial. Clin Infect Dis 2005; 41: 1531-1534.

35 Dow G, Rao P, Harding G, Brunka J, Kennedy J, Alfa M et al. A prospective, randomized trial of 3 or 14 days of ciprofloxacin treatment for acute urinary tract infection in patients with spinal cord injury. Clin Infect Dis 2004; 39: 658-664.

36 Dow G, Thompson M, Harding G, Nicolle L. A double-blind randomized comparison of three versus fourteen days of ciprofloxacin in spinal cord injured (SCl) patients with acute symptomatic urinary tract infection (UTI). Clin Infect Dis 1997; 25: 463.

37 Levi R, Hultling C, Seiger A. The Stockholm Spinal Cord Injury Study: 2. Associations between clinical patient characteristics and post-acute medical problems. Paraplegia 1995; 33: 585-594.

38 Biering-Sorensen F, Hoiby N, Nordenbo A, Ravnborg M, Bruun B, Rahm V. Ciprofloxacin as prophylaxis for urinary tract infection: prospective, randomized, cross-over, placebo controlled study in patients with spinal cord lesion. (Erratum appears in J Urol 1994, 151: 1032). J Urol. 1994;151:105-108.

39 Gribble MJ, Puterman ML. Prophylaxis of urinary tract infection in persons with recent spinal cord injury: a prospective, randomized, double-blind, placebo-controlled study of trimethoprim-sulfamethoxazole. Am J Med 1993; 95: 141-152.

40 Menon EB, Tan ES. Urinary tract infection in acute spinal cord injury. Singapore Med J 1992: 33: 359-361.

41 Wyndaele JJ. Chronic prostatitis in spinal cord injury patients. Paraplegia 1985; 23 : 164-169.

42 Maynard FM, Diokno AC. Urinary infection and complications during clean intermittent catheterization following spinal cord injury. J Urol 1984; 132: 943-946.

43 Sugarman B, Brown D, Musher D. Fever and infection in spinal cord injury patients. JAMA 1982; 248: 66-70.

44 Noreau L, Proulx P, Gagnon L, Drolet M, Laramee MT. Secondary impairments after spinal cord injury: a population-based study. Am J Phys Med Rehabil 2000; 79 526-535.

45 Chang HT, Evans CT, Weaver FM, Burns SP, Parada JP. Etiology and outcomes of veterans with spinal cord injury and disorders hospitalized with community-acquired pneumonia. Arch Phys Med Rehabil 2005; 86: 262-267.

46 Burns SP, Weaver FM, Parada JP, Evans CT, Chang H, Hampton RY et al. Management of community-acquired pneumonia in persons with spinal cord injury. Spinal Cord 2004: 42: 450-458.

47 Evans C, Weaver F, Rogers T, Rapacki L, Miskevics S, Hahm B et al. Guidelinerecommended management of community-acquired pneumonia in veterans with spinal cord injury. Top Spinal Cord Inj Rehabil 2012; 18: 300-305.

48 Backhaus M, Citak M, Tilkorn DJ, Meindl R, Schildhauer TA, Fehmer T. Pressure sores significantly increase the risk of developing a Fournier's gangrene in patients with spina cord injury. Spinal Cord 2011; 49: 1143-1146.

49 Heym B, Rimareix F, Lortat-Jacob A, Nicolas-Chanoine MH. Bacteriological investigation of infected pressure ulcers in spinal cord-injured patients and impact on antibiotic therapy. Spinal Cord 2004; 42: 230-234.

50 Maeder K, Ginunas VJ, Montgomerie JZ, Canawati HN. Methicillin-resistant Staphylococcus aureus (MRSA) colonization in patients with spinal cord injury. Paraplegia 1993; 31: 639-644. 
51 Médée B, Girard R, Loukili A, Loiseau K, Tell L, Rode G. Lower respiratory events in seated tracheotomized tetraplegic patients. Eur J Phys Rehabil Med 2010; 46: 37-42.

52 Clark DE, Lowman JD, Griffin RL, Matthews HM, Reiff DA. Effectiveness of an early mobilization protocol in a trauma and burns intensive care unit: a retrospective cohort study. Phys Ther 2013; 93: 186-196.

53 Morton SC, Shekelle PG, Adams JL, Bennett C, Dobkin BH, Montgomerie J et al. Antimicrobial prophylaxis for urinary tract infection in persons with spinal cord dysfunction. Arch Phys Med Rehabil 2002; 83: 129-138.

54 Joshi A, Darouiche RO. Regression of pyuria during the treatment of symptomatic urinary tract infection in patients with spinal cord injury. Spinal Cord 1996; 34: 742-744.

55 Lewis RI, Carrion HM, Lockhart JL, Politano VA. Significance of asymptomatic bacteriuria in neurogenic bladder disease. Urology 1984; 23: 343-347.
56 Jayawardena V, Midha M. Significance of bacteriuria in neurogenic bladder. J Spinal Cord Med 2004; 27: 102-105.

57 Elden H, Hizmetli S, Nacitarhan V, Kunt B, Goker I. Relapsing significant bacteriuria: effect on urinary tract infection in patients with spinal cord injury. Arch Phys Med Rehabil 1997; 78: 468-470.

58 Livesley NJ, Chow AW. Infected pressure ulcers in elderly individuals. Clin Infect Dis 2002; 35: 1390-1396.

59 Anson CA, Shepherd C. Incidence of secondary complications in spinal cord injury. Int J Rehabil Res 1996; 19: 55-66.

60 Department of Veterans Affairs VHA. Guidelines for Implementation of MRSA Prevention Initiative in the Spinal Cord Injury Centers. 2008. http://www.queri.research.va. gov/tools/sci_mrsa/SCIMRSAGuidelines.pdf.

Supplementary Information accompanies this paper on the Spinal Cord website (http://www.nature.com/sc) 